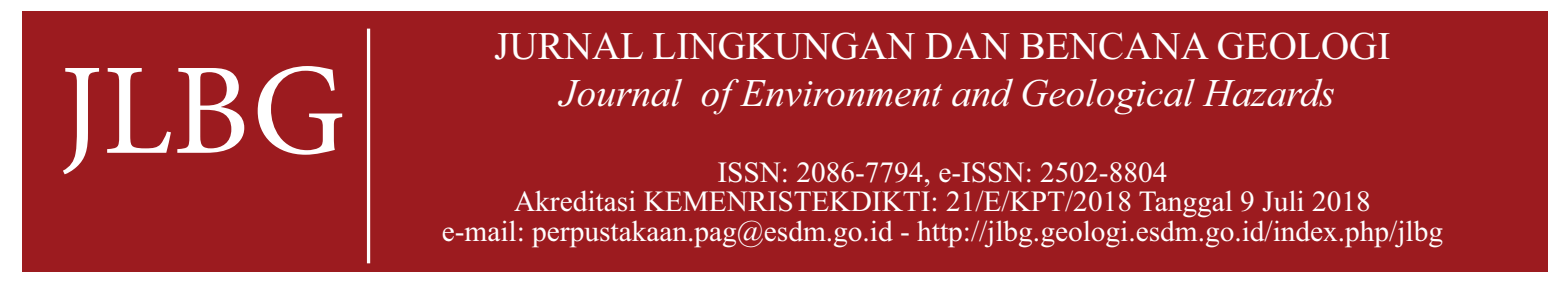

\title{
Interpretasi Bawah Permukaan Gunung Merapi dengan Metode Magnetotellurik
}

\section{Subsurface Interpretation of Merapi Volcano with Magnetotelluric Method}

\author{
Ilham Nurdien, Sulistyani, Anas Handaru, Dewi Sri Sayudi, dan Agus Budi Santoso \\ Balai Penyelidikan dan Pengembangan Teknologi Kebencanaan Geologi \\ Jalan Cendana No 15 Yogyakarta 55166 Indonesia \\ e-mail: ilhamnd@gmail.com \\ Naskah diterima 20 April 2018, selesai direvisi 10 Desember 2020, dan disetujui 15 Desember 2020
}

\begin{abstract}
ABSTRAK
Survei magnetotellurik (MT) telah dilakukan di Gunung Merapi dengan menggunakan alat Phoenix Geophysics MTU5 pada Oktober 2016 dan Mei 2017. Pengukuran dilakukan dengan jarak tiap titik sekitar $1 \mathrm{~km}$, durasi pengukuran untuk satu titik \pm 12 jam, dan lebar dipole $50 \mathrm{~s} / \mathrm{d} 80$ meter utara-selatan dan timur barat. Sebanyak 8 titik sounding digunakan untuk menyusun profil resistivitas 2-D di lereng utara dan selatan. Hasil menunjukkan bahwa resistivitas bawah permukaan Merapi terdiri dari 2 (dua) karakteristik nilai resistivitas yaitu zona resistivitas tinggi dengan nilai 183-50.000 ohm.m dan zona resistivitas rendah dengan nilai 20-175 ohm.m. Zona resistivitas tinggi dapat diinterpretasikan sebagai zona produk erupsi sebelumnya yaitu aliran lava dan material piroklastik lainnya. Sedangkan zona resistivitas rendah diinterpretasikan sebagai kantong magma terbagi menjadi dua bagian, bagian atas berada pada kedalaman $0 \mathrm{~s} / \mathrm{d} 2.000$ meter dengan diameter mencapai 1.000 meter yang mengindikasikan sebuah kantong magma dangkal, sedangkan bagian bawah terlihat menerus dari kedalaman $3.000 \mathrm{~s} / \mathrm{d} 11.000$ meter sebagai kenampakan dapur magma yang cukup besar dengan diameter rata-rata sekitar 2.000 meter yang diindikasikan sebagai kantong magma dalam. Hasil zonasi ini senada dengan posisi hiposenter dari kejadian gempa vulkanik periode tahun 2010. Selain itu, terlihat adanya struktur yang diindikasikan sebagai sesar yang memotong lintasan di sekitar puncak.
\end{abstract}

Kata kunci: Gunung Merapi, kantong magma, magnetotellurik, resistivitas

\section{ABSTRACT}

Magnetotelluric (MT) survey has been carried out on Phoenix Geophysics MTU-5 in October 2016 and May 2017. The measurement has been done with the distance between them approximately $1 \mathrm{~km}$, its duration of each sounding was 12 hours, and dipole length varied from 50-80 meters on North-South and East-West direction. Here we use the result from 8 MT sounding to construct a 2-D electrical resistivity image of the northern and southern flank of Merapi. The results show that the subsurface resistivity in Merapi consists of two types of resistivity features, i.e. the high resistivity zone which having resistivity value 183-50.000 ohm.m and the low one which varied from 20-175 ohm.m. The high resistivity zone are the lava flow and another pyroclastic material, while the low resistivity zone interpreted as magma chamber divided into two parts: upper part, at a depth of 0-2,000 meters with 1,000 meters diameter which is indicated as a shallow magma chamber, lower part, continuously from the depth of 3,000-11,000 meters as the large magma chamber with an average diameter of about 2,000 meters. The zone can be correlated to the hypocenter position taken from the volcanic earthquake event of 2010 period. In addition, there is a structure which indicated as a fault that cuts the trajectory around the summit.

Keywords: Merapi Volcano, magma chamber, magnetotelluric, resistivity

\section{PENDAHULUAN}

Setelah Erupsi 2010 banyak sekali perubahan perilaku Gunung Merapi yang meliputi perubahan aktivitas seismik, tipe gempa, deformasi, dll (Budi-Santoso, drr.,2013). Berbagai kajian dilakukan untuk lebih memahami karakter baru Merapi, salah satunya adalah dengan melakukan pemetaan struktur bawah permukaannya. 
Pemetaan struktur bawah permukaan dapat dilakukan menggunakan metode gravitasi, geomagnet, Audio Magnetotelluric, Magnetotellurik, geolistrik dan Self Potential (Wynn, Jeffrey. 2006). Hasil pengukuran dari berbagai metode tersebut akan saling mendukung satu sama lain. Hal ini dikarenakan anisotropi medium dalam area Merapi cukup kompleks sehingga kadangkadang menimbulkan ambiguitas hasil analisa bila hanya mengandalkan satu metode saja. Dengan pengukuran dengan metode magnetotellurik ini diharapkan dapat lebih mempertegas hasil analisa yang telah dilakukan sebelumnya mengenai gambaran bawah permukaan Merapi dengan lebih rinci.

Metode magnetotellurik digunakan dalam penelitian ini karena memiliki penetrasi bawah permukaan yang sangat dalam serta memiliki resolusi vertikal yang cukup bagus untuk menggambarkan sebaran nilai resistivitas bawah permukaan daerah penelitian.

Penelitian dilaksanakan pada bulan Oktober 2016 dan Mei 2017. Lokasi penelitiannya di lereng utara dan selatan Gunung Merapi di sekitar jalur pendakian Newselo-Pasarbubar dan Kinahrejo-Kendit dengan posisi sekitar 7³2’30” LS dan $110^{\circ} 26^{\prime} 30^{\prime \prime}$ BT. Peta lokasi daerah penelitian dapat dilihat pada Gambar 1 dan 2.

Berdasarkan tataan tektoniknya, Gunung Merapi terletak pada zona subduksi, di mana Lempeng Indo-Australia menunjam di bawah Lempeng Eurasia (Hamilton, 1979). Merapi muncul di bagian selatan dari jajaran kelurusan gunungapi di Jawa Tengah mulai dari utara ke selatan yaitu Ungaran -Telomoyo -Merbabu dan Merapi.

Merapi merupakan gunungapi berbentuk strato, yang menurut van Bemmelen (1949), periodenya dimulai dari fase Merapi Tua yang mulai terbentuk pada masa Pleistosen. Secara geologi (Berthomier, 1990) membagi perkembangan Merapi dalam empat periode yaitu Pra-Merapi sejak 700.000 tahun lalu yang menyisakan Gunung Bibi yang berkomposisi andesit basaltik. Merapi Tua terjadi ketika Merapi mulai terbentuk tetapi belum berbentuk kerucut (60.000 8000 tahun lalu). Sisa-sisa tahap ini adalah Bukit Turgo dan Bukit Plawangan di bagian selatan, yang terbentuk dari lava basalt. Selanjutnya Merapi Pertengahan (8000-2000 tahun lalu),

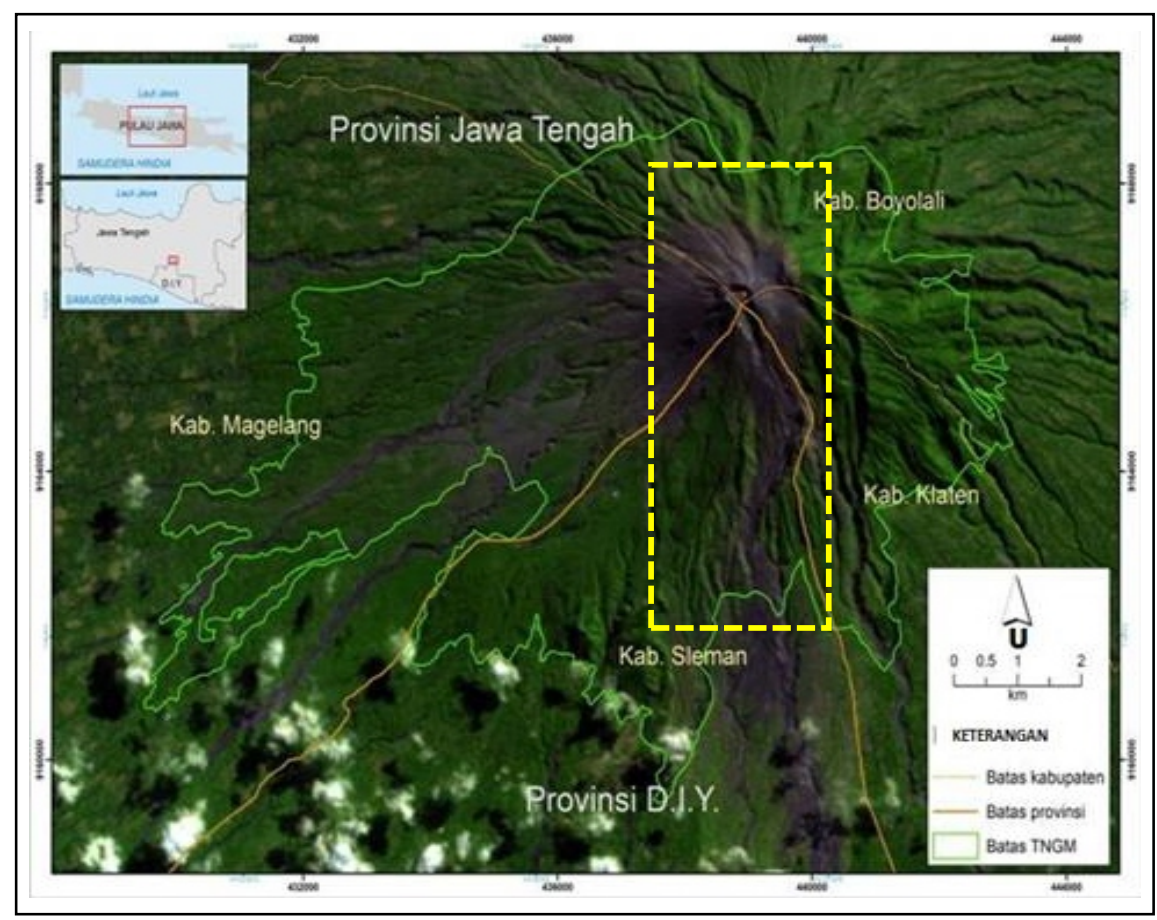

Gambar 1. Lokasi daerah Penelitian (Latifiana, 2018). 


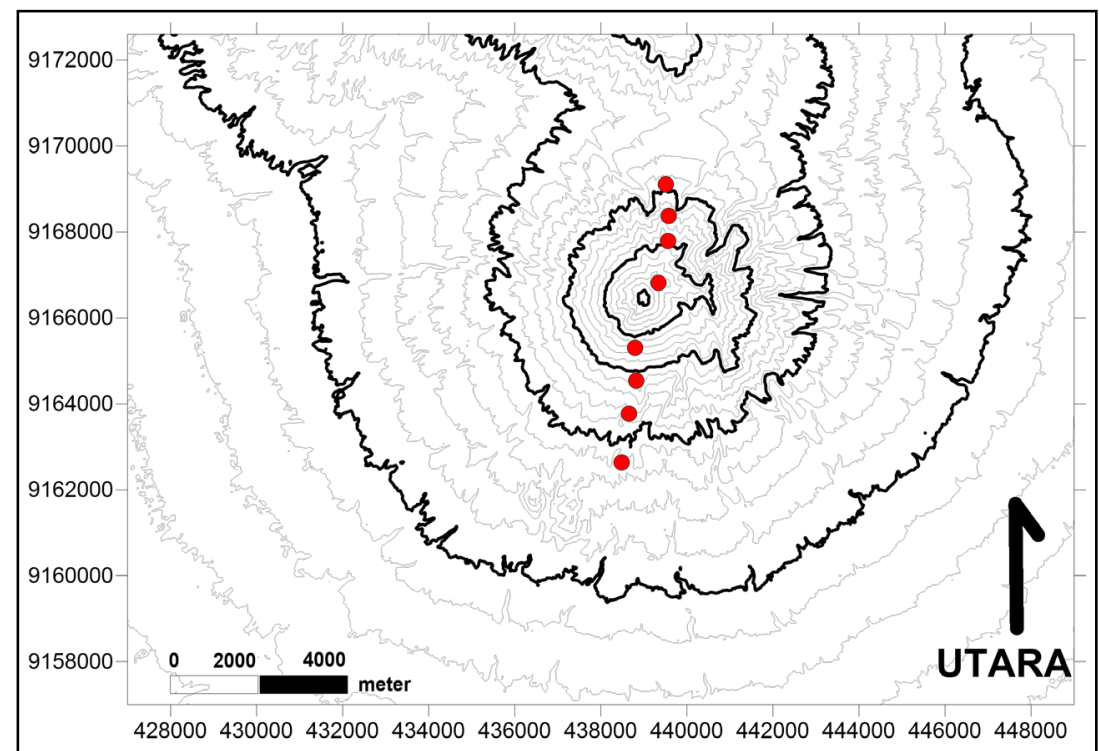

Gambar 2. Posisi titik pengukuran magnetotellurik dioverlay diatas peta kontur G. Merapi.

yang ditandai dengan terbentuknya puncakpuncak tinggi, seperti Bukit Gajahmungkur dan Batulawang, yang tersusun dari lava andesit. Merapi Baru (2000 tahun lalu - sekarang) menghasilkan awan panas Tipe Merapi dan kubah lava yang berkomposisi andesit basaltik. Selanjutnya Berthomier (1990), Newhall \& Bronto (1995), Newhall., drr. (2000) menemukan unit-unit stratigrafi di Merapi yang semakin rinci. Sri-Sayudi (2015), menyatakan batuan lava Merapi Tua ber-komposisi basalt-andesit basaltik, sedangkan batuan Merapi Pertengahan/ Muda dan Merapi Baru berkomposisi andesit basaltik - andesit.

\section{LANDASAN TEORI}

Metode magnetotellurik (MT) adalah metode elektromagnetik untuk mengukur fluktuasi medan magnet dan merekam fluktuasi medan listrik di permukaan Bumi. Sumber fluktuasi medan elektromagnetik ini berasal dari aktivitas meteorologi dan aliran arus listrik di ionosfer (Telford., drr. 1976) (Gambar 3).

MT ini mempunyai jangkauan frekuensi yang lebar, antara 0.001-10000 Hz. Selain itu, metode magnetotelurik dapat juga menggunakan sumber medan elektromagnetik buatan yang dapat diatur

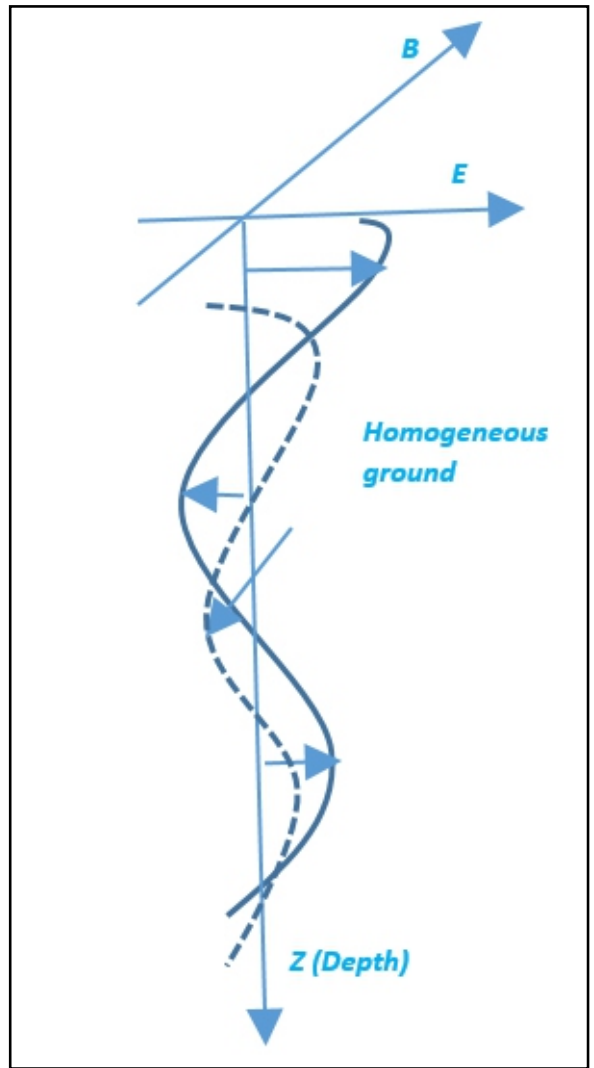

Gambar 3. Konfigurasi komponen medan listrik dan medan magnet diukur dengan metode magnetotellurik. (Telford., drr. 1976).

frekuensinya. MT yang menggunakan sumber buatan ini dikenal dengan nama metode CSAMT (Controlled Source Audio Magnetotelluric). 
MT mempunyai daya jangkau spektrum frekuensi yang lebar, dalam interaksinya medan elektromagnetik dengan tanah akan menghasilkan medan induksi sekunder yang dikontrol oleh sifat-sifat kelistrikan tanahnya (Vozzof, 1991). Dalam survei MT baik medan primer maupun medan sekunder yang terukur adalah medan totalnya saja. Hubungan antara fluktuasi medan listrik dan medan magnet dirumuskan dalam Persamaan Maxwell dan Hukum Ohm.

Penurunan rumus MT dikembangkan dengan mengikuti pendekatan Cagniard (1953) dengan asumsi bumi memiliki sifat listrik yang homogen isotropik dan mengasumsikan gelombang elektromagnetik alam yang berinteraksi dengan bumi adalah gelombang bidang (plane wave) di mana medan magnet dan medan listrik saling tegak lurus satu sama lain. Karena medan magnet berubah terhadap waktu, maka arus listrik induksi di dalam bumi dapat dijelaskan dengan teori Maxwell (1865).

Dalam kasus dua dimensi, Persamaan Maxwell (1865) untuk gelombang elektromagnetik terbagi atas dua bentuk mode polarisasi. Pertama, sebagai TE-mode (E-polarisasi) di mana satu medan listrik (Ex) sejajar terhadap arah strike di sepanjang sumbu $x$ dan dua medan magnet (Hy dan Hz) berada dalam bidang Y-Z. Kedua, TM-mode (H-polarisasi), di mana satu medan magnet $(\mathrm{Hx})$ sejajar arah strike di sepanjang sumbu $x$ dan dua medan listrik (Ey dan Ez) dalam bidang Y-Z. Dalam suatu frekuensi tertentu perubahan sinusoidal amplitudo kuat medan magnet dan kuat medan listrik pada dua arah yang saling tegak lurus dalam selang waktu yang singkat adalah $\Delta \mathrm{Hx}(\mathrm{nT})$ dan $\Delta \mathrm{Ey}(\mathrm{mV} /$ $\mathrm{km})$ dengan mengasumsikan bumi homogen dan hasil penurunan lebih lanjut teori Maxwell (1865) diperoleh hubungan antara tahanan jenis, kuat medan listrik (E), kuat medan magnet $(\mathrm{H})$ dan frekuensi (f) sebagai berikut:

$$
\rho=0.2 T\left|\frac{\Delta E_{x}}{\Delta H_{y}}\right|^{2}
$$

Jika bumi tidak homogen, maka persamaan di atas mendefinisikan tahanan jenis semu.

Gelombang bidang yang masuk ke dalam permukaan bumi homegen akan teranenuasi terhadap kedalaman z diberikan oleh:

$\exp \left\{-(\pi f \mu \sigma)^{1 / 2} z\right\}$

dengan $\mathrm{f}$ frekuensi, permeabilitas magnetik medium, konduktivitas listrik.

Tingkat kedalaman optimal gelombang elektromagnetik yang menembus bumi mengalami penurunan intensitas (atenuasi) dari kuat medan aslinya sebesar 1/e didefinisikan sebagai skin depth, diberikan:

$$
\delta=\frac{1}{(\pi f \mu \sigma)^{1 / 2}}=0.5(\rho T)^{1 / 2} k
$$

Kedalaman efektifnya (d) dinyatakan sebagai:

$$
d=\frac{\delta}{\sqrt{2}}=0.5\left(\frac{\rho T}{2}\right)^{1 / 2} \mathrm{~km}
$$

Dari persamaan di atas terlihat bahwa semakin kecil frekuensi medan maka semakin dalam penetrasinya sehingga pada frekuensi rendah tahanan jenis terhitung mencerminkan sifat fisik batuan di kedalaman besar.

\section{METODE PENELITIAN}

Akuisisi data dilakukan menggunakan instrumen magnetotellurik dari Phoenix Geosystem seri MTU-5, pengukuran dilakukan sebanyak 8 titik dengan orientasi lintasan utara-selatan, jarak antar titik sekitar $1 \mathrm{~km}$ dengan lebar $d i-$ pole bervariasi menyesuaikan kondisi lapangan. Akuisisi dilakukan dengan durasi rata-rata 12 jam. Penentuan jumlah dan posisi titik mempertimbangkan perkiraan posisi dan besar target utama bawah permukaan yang akan dipetakan (kantong magma) (Gambar 4).

Pemrosesan data lapangan berupa file Raw Time Series dalam format ekstensi (.TS), file Calibra- 


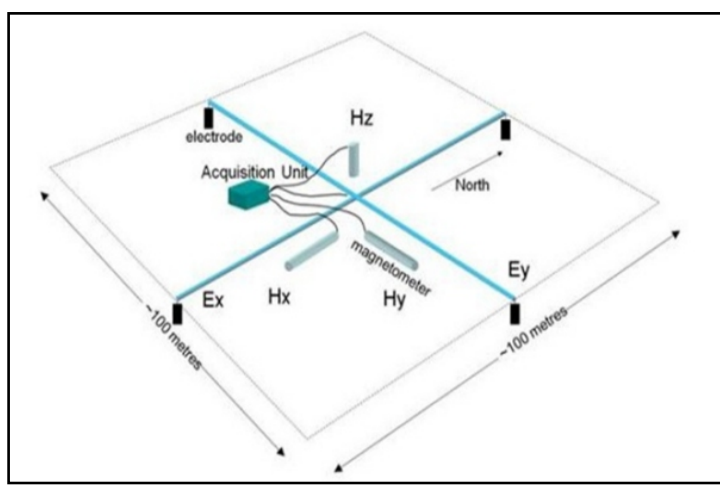

Gambar 4. Konfigurasi sensor di lapangan.

tion yang terdiri dari kalibrasi instrumen atau kalibrasi box dalam format ekstensi (.CLB) dan kalibrasi sensor atau kalibrasi coil dalam format ekstensi (.CLC), serta file Site Parameter dalam format ekstensi (.TBL). Selanjutnya data ini akan dilakukan proses edit parameter dan robust dengan menggunakan program SSMT2000 yang akanmenghasilkan data output berupa data plot MT dalam format ekstensi (.MTH) yang berisi data yang berfrekuensi tinggi dan (.MTL) berisi data dengan frekuensi rendah dan akan diedit pada program MT-Editor. Output yang didapatkan kemudian dilakukan proses smoothing dan editing data dengan menggunakan perangkat lunak MT Editor dari Phoenix Geophysic Canada, dilakukan seleksi crosspower dengan membagi data MT ke dalam beberapa segmen dengan ukuran yang sama untuk memperbaiki kurva resisitivitas agar lebih smooth serta disesuaikan dengan kurva fasa-nya. Setelah didapatkan kurva resistivitas yang lebih baik kemudian dilakukan export kedalam format ektensi (.edi) untuk dilakukan proses pembuatan model (Gambar 5).

\section{HASIL DAN PEMBAHASAN}

Kurva nilai resistivitas yang didapatkan dari proses pengolahan data awal menunjukkan kualitas data yang cukup bagus dengan melihat bentuk kurva tahanan jenis semu yang smooth, error dan noise yang cukup sedikit serta dengan melihat kesesuaian kurva tahanan jenis dengan fase. Hasil proses awal berdasarkan bentuk dan nilai kurva tahanan jenis semu menunjukkan

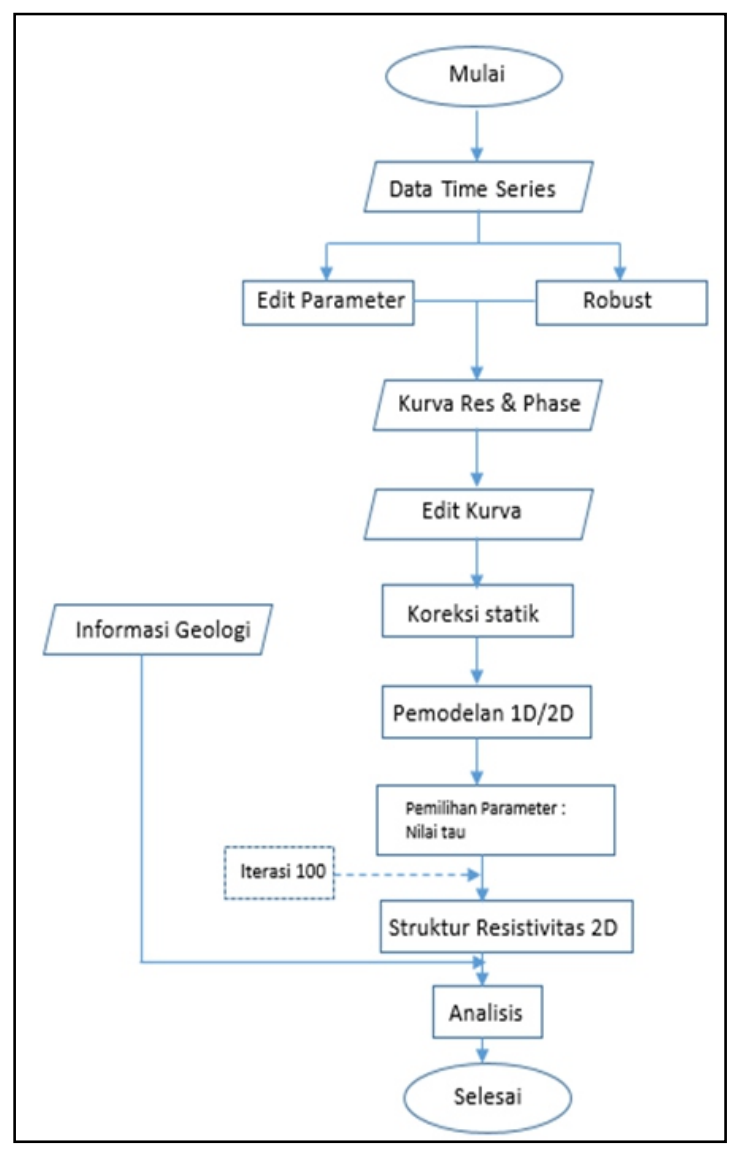

Gambar 5. Diagram alir pengolahan data.

adanya kenampakan nilai resistivitas rendah yang terekam pada semua titik (Gambar 6). Proses inversi 2D dilakukan terhadap kurva tahanan jenis semu untuk mendapatkan gambaran sebaran resistivitas bawah permukaan yang lebih jelas. Hasil inversi menunjukkan anomali resistivitas rendah $(2 \mathrm{~s} / \mathrm{d} 10 \mathrm{Ohm}$.meter) berada di bawah puncak Merapi yang menerobos dari bawah menembus batuan yang memiliki nilai anomali resistivitas tinggi (Gambar 7).

Anomali resistivitas rendah yang menerobos dari bawah terlihat terpisah pada kedalaman sekitar 2000 meter dari puncak Merapi sehingga terlihat terbagi menjadi dua bagian yaitu bagian atas dan bagian bawah.

Anomali resistivitas rendah ini diindikasikan sebagai magma chamber Merapi (Gambar 7) sehingga bisa dikatakan bahwa magma chamber Merapi terpisah menjadi 2 bagian yaitu bagian atas/dangkal dan bagian bawah/dalam. Kantong 


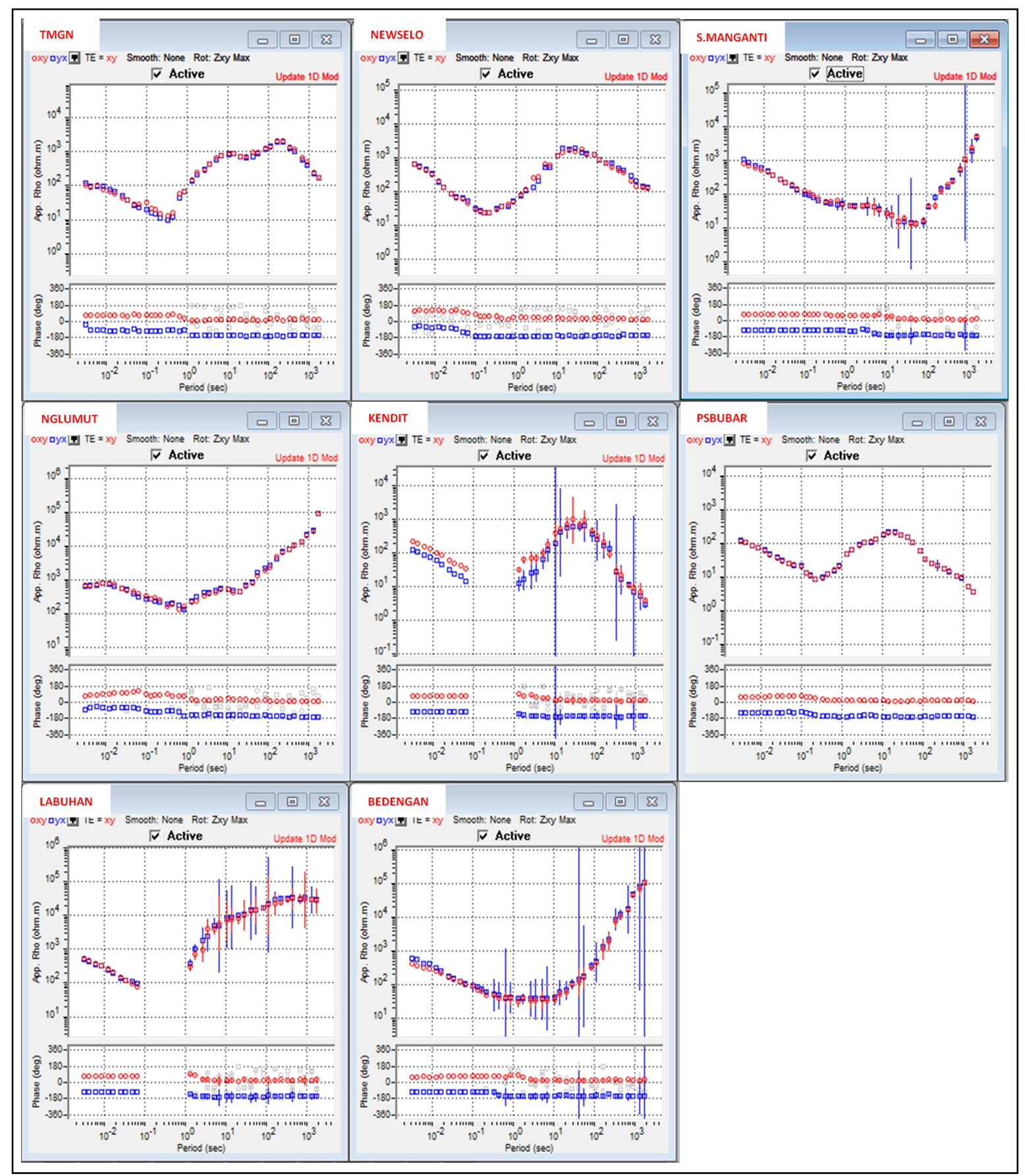

Gambar 6. Kurva log tahanan jenis semu titik pengukuran magnetotellurik secara kualitatif menunjukkan adanya anomali resistivitas rendah terdeteksi di semua titik pengukuran, respon ini dimungkinkan berasal dari kantong magma Gunung Merapi (interpretasi secara kuantitatif dilakukan setelah proses inversi 2D terhadap kurva tersebut).

magma dangkal Merapi diindikasikan berada pada kedalaman $0 \mathrm{~s} / \mathrm{d} 2000$ meter dari puncak, sedangkan kantong magma dalam berada dari kedalaman 2700 meter di bawah puncak dan menerus sampai ke bawah.

Ketidakmenerusan anomali resistivitas rendah pada kedalaman $2000 \mathrm{~m}$ dari puncak dimung- kinkan terdapat semacam struktur pada area tersebut sehingga suplai magma dari bawah terlihat seperti tertahan pada area itu. Dengan melihat pola dan gap anomali resistivitas yang terlihat pada area tersebut dimungkinkan struktur tersebut berupa patahan. Hal ini diperkuat dengan hasil plot sebaran hiposenter dari 518 


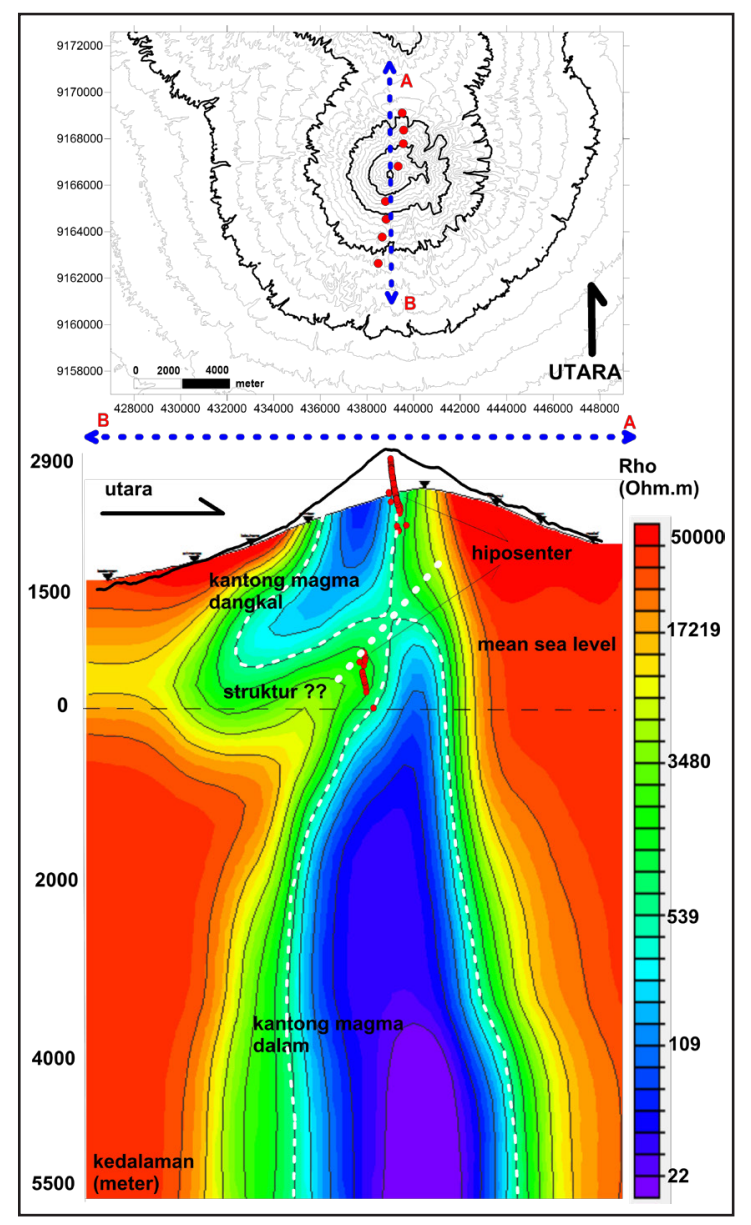

Gambar 7. Sebaran nilai resistivitas hasil inversi 2D pada lintasan pengukuran magnetotellurik yang dioverlay dengan hiposenter gempa.

kejadian gempa Vulkano Tektonik (VT) tahun 2009 - 2010 yang dioverlay dengan model resistivitas (Gambar 7). Penentuan hiposenter dilakukan dengan metode 'double difference' (Waldausseer dan Ellsworth, 2000). Sebaran hiposenter tersebar secara vertikal pada dua rentang kedalaman. Gempa -gempa VTA (VT dalam) berada pada kedalaman antara 2,3 - 3 km di bawah puncak sedangkan gempa - gempa VTB (VT dangkal) tersebar di atas kedalaman 1,5 km (Budi-Santoso, 2014). Zona aseismik yang terletak di antara dua sebaran gempa VTA dan VTB merupakan zona ductile yang dapat diinterpretasikan sebagai sebuah kantong magma dangkal. Kantong magma yang lebih besar diperkirakan berada di bawah sebaran gempa VTA atau $>3$ km (Budi-Santoso, drr., 2013), terlihat adanya ketidaksinambungan anomali resistivitas rendah secara vertikal konsisten dengan zona aseismik yang ditunjukkan oleh sebaran hiposenter gempa VT. Anomali resistivitas rendah yang terdeteksi pada kedalaman $>2700$ m diperkirakan berkaitan dengan adanya sebuah dapur magma/kantong magma dalam. Sedangkan anomali resistivitas rendah pada kedalaman $<2000$ m sesuai dengan keberadaan sebuah kantong magma dangkal.

Kedua kantong magma tersebut dihubungkan oleh sebuah sistem dike yang ditunjukkan oleh sebaran gempa VT. Gempa VT ini terjadi akibat rusaknya batuan sekitar dike akibat tekanan dari pergerakan magma yang melewatinya. Sistem dike serupa menjadi jalan keluar bagi magma dari kantong magma dangkal ke permukaan puncak.

\section{KESIMPULAN}

Hasil pengukuran magnetotellurik dengan lintasan dengan orientasi utara-selatan di Gunung Merapi menunjukkan adanya kenampakan magma chamber pada kedalaman $0 \mathrm{~s} / \mathrm{d} 2000$ meter dari puncak dan pada kedalaman 2700 meter menerus kebawah yang dipisahkan oleh struktur pada kedalaman 2000 meter yang diperkirakan sebuah sistem dike. Dugaan sistem dike ini diperkuat dengan melihat pola sebaran hiposenter yang cenderung terpusat di ujung bagian atas tubuh konduit. Adapun diameter magma chamber tersebut bervariasi dari $1000 \mathrm{~s} / \mathrm{d} 2000$ meter.

\section{UCAPAN TERIMA KASIH}

Penulis mengucapkan terima kasih kepada seluruh anggota tim survei magnetotellurik yang telah membantu mengumpulkan data penelitian. Ucapan terima kasih juga disampaikan kepada rekan-rekan pengamat Merapi dan rekan-rekan warga Plalangan atas dukungan dan bantuannya selama akuisisi data di lapangan.

\section{DAFTAR PUSTAKA}

Bemmelen, van, R.W. 1949. The Geology of Indonesia. Martinus Nijhoff, The Haque, Nederland. 
Berthomier. 1990. Etude volcanologique du Merapi (Centre-Java) Te'phrostratigraphic et Chronologie - produits eruptifs. University of Blaise Pascal, France.

Budi-Santoso, A. 2014. The seismic activity associated with the large 2010 eruption of Merapi volcano, Java: source location, velocity variation, and forecasting. Ph.D Thesis. University of Grenoble, Grenoble, France.

Budi-Santoso, A., Lesage, P., Dwiyono, S., Sumarti, S., Subandriyo, Surono, Jousset, P., Metaxian, J.-P. 2013. Analysis of the seismic activity associated with the 2010 eruption of Merapi Volcano, Java. Dalam: Journal of Volcanology and Geothermal Research 261, 153 -170.

Cagniard, L. 1953. Basic Theory of The Magnetotelluric Method of Geophysical Prospecting.

Hamilton, W.R. 1979. Tectonics of the Indonesian Region. US Geological Survey Professional Paper.

Latifiana, K. 2018. Pemetaan Habitat Potensial Herpetofauna pada Daerah Terdampak Erupsi Gunung Merapi 2010.

Maxwell, J.C. 1865. A Dynamical Theory of the Electromagnetic Field. Dalam: Philosophical Transaction of Royal Society of London.

Newhall, C.G., Bronto, S. 1995. An Explosive history of Merapi volcano. Dalam: Merapi De-cade Volcano, International Workshop, Abstract and Program, October.

Newhall, C.G., Bronto, S., Alloway, B.V., Banks, N.G., Bahar, I., Del Marmol, M. A.,
Hadisantono, R., Andreastuti, S., Tilling, R.I., Torley, R., Trimble, D., Wirakusumah, A.D. 2000. 10,000 years of explosive eruptions of Merapi volcano, Central Java: Archaelogical and modern implications. Dalam: Journal of Volcanology and Geothermal Research.

Sri-Sayudi, D. 2015. Studi Geokimia Batuan Lava G. Merapi. Laporan kegiatan lapangan BPPTKG.

Telford, W.M., Goldrat, L.P., Sheriff, R.P. 1976. Applied Geophysics $1^{\text {st }}$ ed. Cambridge University Pres, Cambridge.

Vozzoff, K. 1991. The magnetotelluric method. Dalam: Electromagnetic Methods in Applied Geophysics - vol. 2. Application, M.N. Nabighian (ed.). SEG Publishing.

Waldhauser, F., Ellsworth, W.L. 2000. A DoubleDifference Earthquake Location Algorithm: Method and Application to the Northern Hayward Fault, California. Dalam: Bulletin of the Seismological Society of America 90, $1353-1368$.

Wynn, Jeffrey, Daniel Dzurisin, Carol A. Finn, James P. Kauahikaua, and Richard G. Lahusen. 2006. Application of geophysical methods to volcano monitoring. Dalam: Journal of Environmental \& Engineering Geophysics : Proceedings volume of the Symposium for the Application of Geophysical Methods to Environmental \& Engineering Problems, the annual meeting of the Environmental and Engineering Geophysical Society, Seattle, WA, April 2-6, 2006.. 174-183. 